\title{
Metodologia Científica no Brasil: ensino e interdisciplinaridade
}

Américo Augusto Nogueira Vieira' Ademir Clemente' Guilherme Ataíde Dias" Marcílio Toscano Franca Filho"

'Universidade Federal do Paraná (UFPR), Curitiba/PR - Brasil "Universidade Federal da Paraíba (UFPB), João Pessoa/PB - Brasil

RESUMO - Metodologia Científica no Brasil: ensino e interdisciplinaridade. O problema da demarcação não tem sido satisfatoriamente exposto nas disciplinas de Metodologia. São raras as exposições do Método HipotéticoDedutivo, sua natureza e seu emprego, na mencionada disciplina. Este artigo resulta de pesquisa das práticas da disciplina de Metodologia Científica. A pesquisa abrangeu ampla base bibliográfica e apresenta contribuições no sentido de aprimorar o ensino-aprendizagem e corrigir equívocos contidos na maioria dos textos didáticos. A conclusão é que a reorientação da disciplina representa oportunidade para aprimoramento da prática interdisciplinar, e favorece a prática de isomorfismos, o desenvolvimento de perspectivas sistêmicas e o avançar para a transciência.

Palavras-chave: Metodologia Científica. Demarcação. Método HipotéticoDedutivo. Interdisciplinaridade. Ensino.

ABSTRACT - Scientific Methodology in Brazil: teaching and interdisciplinarity. The problem of demarcation has not been satisfactorily explained in the disciplines of Methodology. Explanations about the Hypothetical-Deductive Method, its nature and its use are scarce. This article is the result of a research on the practicing of the Scientific Methodology discipline. The research covered a wide bibliographical database, and represents a contribution towards improving the teaching-learning process and correcting misconceptions encountered in most textbooks. The conclusion is that the reorientation of the discipline is an opportunity to enhance the interdisciplinary practice, and promotes the practice of isomorphism, the development of systematic perspectives and the advance towards transcience.

Keywords: Scientific Methodology. Demarcation. Hypothetical-Deductive Method. Interdisciplinarity. Teaching.

Educação \& Realidade, Porto Alegre, v. 42, n. 1, p. 237-260, jan./mar. 2017. 237 http://dx.doi.org/10.1590/2175-623654484 


\section{Introdução}

O estudo da Metodologia Científica (ou Metodologia do Trabalho Científico, Metodologia da Ciência ou da Ciência X, etc.) é obrigatório na maioria dos cursos de graduação e de pós-graduação no Brasil. O conteúdo programático dessa disciplina geralmente abrange confecção e normalização de trabalhos acadêmicos, em geral monografias, bem como apresentação aos alunos da natureza da ciência e do Método Científico. Este Método Científico é composto de vários submétodos e técnicas, alguns dependendo do campo de conhecimento e dependendo dos objetos sobre os quais incidem.

Para uma ampla variedade de estudos científicos o Método Hipotético-Dedutivo é uno, ainda que com o passar do tempo venha sendo apresentado de forma cada vez mais esquemática. Ver-se-á que a querela de que cada ciência deve possuir seus métodos próprios nada tem a ver com o Método Hipotético Dedutivo em sentido estrito, e sim com os métodos de validação de enunciados (de hipóteses e de conclusões) e das operações e transformações que são, estas sim, próprias de cada área do saber científico. A Lógica tradicional, doravante referida como Lógica Crisp (para diferenciar de outras lógicas, como a Fuzzy e as famílias das lógicas paraconsistentes, modal etc.) é a ciência que desenvolve o Método Hipotético-Dedutivo ainda que, além das operações basilares da Lógica Crisp, existam variadas operações, procedimentos, técnicas que validam as referidas inferências nos mais diversos campos do saber. Este artigo analisa e discute alguns aspectos relevantes desta última parte do programa da referida disciplina: o Método Hipotético-Dedutivo.

Além disso, pesquisadores já alertam que uma vez superada a fase multidisciplinar, atingindo-se a interdisciplinaridade, vislumbrar-seia uma nova fase, denominada transciência, o que torna extremamente oportuno e útil realizarmos a análise isomórfica entre áreas do saber, visando o desenvolvimento e o aperfeiçoamento dos corpos teóricos. Nesse diapasão o Instituto Santa Fé (EUA) aponta a necessidade de se observarem certos investimentos em aprendizagem (Krakauer 2011, p. 2, tradução nossa) $)^{1}$ :

Eu acredito que estamos entrando em um período de transciência, em que está se tornando necessário que o treinamento em áreas nas quais os princípios fundamentais da matemática, computação e lógica deveriam ser emancipados de uma única classe de estudos de casos historicamente contingentes. Por exemplo, a física estatística vai continuar a ser útil para a compreensão dos fenômenos sociais, como, tradicionalmente, tem sido no estudo das propriedades da matéria condensada.

Assim, se pensarmos que a maioria das ciências vem adotando uma perspectiva sistêmica (particularmente para o Direito o estudo dos ordenamentos jurídicos como sistema é um exemplo até trivial de adesão ao sistemismo; como, por exemplo, em Norberto Bobbio, 2011), então deveríamos nos habituar a cotejar com o que já ocorreu ou ocorre 
em outros campos do saber científico. Vejamos o que nos aponta Bertalanffy (2012, p. 58):

De fato, conceitos, modelos e leis similares apareceram muitas vezes em campos bastante diferentes, independentemente e com base em fatos totalmente diferentes. Há muitos casos em que princípios idênticos foram descobertos várias vezes porque os pesquisadores que trabalhavam em um campo ignoravam que a estrutura exigida já estava desenvolvida em outro campo.

Desta forma, vencida a questão de ser a Metodologia Científica relevante para o conjunto das ciências, deveremos passar a refletir sobre as diversas concepções de ciência e de Método Científico adotadas em textos universitários brasileiros. Verificamos que há uma variabilidade de concepções sobre a ciência e a prática científica, entre as quais algumas são questionáveis e outras totalmente indefensáveis. Sem querer acusar este ou aquele docente, sem querer estabelecer o rol das incoerências específicas que identificamos em nossas investigações, julgamos oportuno trazer a lume algumas ideias que poderiam contribuir para a melhoria do quadro geral de conhecimento para todos os que se interessam pela disciplina de Metodologia Científica. Os argumentos aqui apresentados têm o sentido de que: (1) a identificação do que é ciência, e do que não o é, não é uma questão trivial como muitos autores de livros didáticos de Metodologia Científica equivocadamente apontam e (2) o Método Hipotético-Dedutivo não é bem conhecido e não se encontra minimamente explicitado na maioria dos livros didáticos de Metodologia Científica de autores brasileiros.

Aqui não será possível uma apresentação sistemática do problema da demarcação devido à limitação de espaço (o que poderia ser mais detidamente visto em A lógica de pesquisa científica de Karl Popper, ou em livros e artigos que tratam exclusivamente sobre esta questão), mas demonstraremos de forma bastante sintética que nos textos didáticos brasileiros isto tem sido desconhecido ou tratado com um simplismo ${ }^{2}$ que não pode ser acatado.

A pesquisa que subsidiou o artigo foi desenvolvida por pesquisadores de diferentes universidades e formações, baseou-se em ampla bibliografia, tendo apenas a pretensão de analisar a situação do ensino de Metodologia Científica com vistas à relevância desta para todas as áreas do conhecimento científico. Os autores de que nos valemos para desenvolver a presente análise crítica das práticas acadêmicas brasileiras são: Karl Popper, Thomas Kuhn, Stiglitz e Walsh, Keynes, Vieira, Russel, Pinguelli Rosa, Bertalanffy, Newton da Costa, Krakauer e Umberto Eco. Sem haver exaurimento das bibliografias de Metodologia brasileiras, o que seria por demais exaustivo, consultamos um conjunto de monografias, dissertações e teses selecionadas aleatoriamente em Ciências Sociais Aplicadas e dessas selecionamos as trinta obras mais encontradas em referências (além de algumas dezenas de apostilas na internet). Após, verificamos a compatibilidade ou eventuais distorções destas com aquelas citadas nos programas de graduação de várias disciplinas de Metodologia. Não en- 
contramos fortes disparidades e, por consequência, mantivemos a amostra para fins da construção do presente texto. Não obstante o fato de alguns dos autores lecionarem (ou já terem lecionado) a referida disciplina.

Cremos que o artigo possa efetivamente representar uma contribuição à disciplina de Metodologia Científica em todas as áreas do conhecimento, especialmente aos que estão se iniciando como docentes ou como pesquisadores. A permanente crítica e reconstrução é característica da ciência e do seu método e, por isso, tem-se também a pretensão de contribuir para o debate que renova e aprofunda constantemente a sua prática.

Finalmente, é bastante comum que a incumbência de ministrar a referida disciplina seja assumida por departamentos de Ciência da Informação ou de Educação, que possuem comprovada expertise nas questões de normalização (um dos três tópicos em que se subdivide a referida disciplina). No Direito, em regra, é um profissional de Direito que ministra a referida disciplina. Nas engenharias, por vezes é ministrado por um profissional com formação em engenharia. Assim, consideramos o presente trabalho plenamente justificado no campo de investigação das várias áreas do saber científico, dado que o estudo dos métodos ou metodologia constitui conhecimento basilar para a prática científica. Não obstante, há também enorme interesse pela matéria na Engenharia de Produção como se pode constatar no seguinte documento da COPPE/UFRJ (2001, p. 142) ${ }^{3}$ :

\begin{abstract}
A Engenharia de Produção se dedica ao estudo, ao projeto e à gerência de sistemas integrados de pessoas, materiais, equipamentos e ambientes, visando à melhoria da produtividade do trabalho, da qualidade do produto e da saúde das pessoas, esta última no que se refere à influência da atividade do trabalho. Dado que a Engenharia de Produção não se insere em uma área específica da tecnologia, caracterizando-se antes como uma 'engenharia de métodos e de procedimentos', a abordagem interdisciplinar tornou-se o caminho histórico da sua construção cognitiva. Assim, os primórdios da especialidade remontam aos estudos da divisão, da organização e da racionalização do trabalho, no início da produção industrial. A partir daí, ela abrangeu os mais diferentes ramos, das telecomunicações à agricultura, da administração à construção civil, do comércio aos serviços.[...]

Ele deve ser, portanto, o ‘engenheiro interdisciplinar' por excelência, no qual a competência técnico-científica se alie a um embasamento humanístico sólido. Esta diversidade de interesses, por outro lado, gerou no Programa uma grande preocupação com as questões relacionadas à metodologia científica, o que conduziu à dedicação de setores específicos a questões com ela relacionadas.
\end{abstract}

Assim, a situação da disciplina e a qualidade das publicações sobre Metodologia no Brasil, como se verá no presente artigo, não são condizentes com a existência de Engenharia de Métodos e profissionais com formação multi e interdisciplinar com potencial para publicar e ministrar com expertise a referida disciplina. No Direito, na Ciência da 
Informação, na Medicina, na Educação, por exemplo, também há vários profissionais com diversificada formação que poderiam muito contribuir para o aperfeiçoamento da referida disciplina.

Este artigo apresenta, na sequência desta introdução, uma seção dedicada ao problema da demarcação e após discute o Método Hipotético-Dedutivo. Apresenta-se, então, uma conclusão.

\title{
O Problema da Demarcação
}

Uma das primeiras questões abordadas em textos de Metodologia Científica é a natureza do conhecimento científico, ou ainda: sobre o que é e o que não é conhecimento científico. Segundo Stiglitz ${ }^{4}$ e Walsh (2003, p. 17) em Introdução à Macroeconomia:

\begin{abstract}
A economia é uma ciência social. Estuda os problemas sociais da escolha do ponto de vista científico, o que quer dizer que parte de uma exploração sistemática do problema da escolha. Essa exploração sistemática envolve tanto a formulação de teorias quanto o exame de dados.
\end{abstract}

Mas construir ou desenvolver teorias e colocá-las à prova é a essência do trabalho não apenas da economia e das ciências sociais. Karl Popper afirma, em sentido amplo, em sua obra A lógica da pesquisa científica (1993, p. 31, grifo nosso): "Afirmei anteriormente que o trabalho do cientista consiste em elaborar teorias e pô-las à prova”. Portanto, a tarefa do cientista é contribuir para o desenvolvimento de teorias, daí a importância de verificar como entendem esses pesquisadores o conceito de teoria.

Retornando ao texto de Stiglitz e Walsh (2003, p. 17, grifo nosso): "Uma teoria é um conjunto de pressuposições (ou hipóteses) e conclusões derivadas dessas hipóteses. As teorias são exercícios lógicos: se a hipótese está correta, então segue-se o resultado”. Neste sentido, vejamos o que nos ensina Vieira (2004, p. 41-42) acerca da afirmação de Stiglitz e Walsh:

É comum, em argumentações, encontrarmos estruturas do tipo:

'Partindo dos dados ora apresentados, é nítido que estes acarretam [...]';

'Vimos, então, que, a partir dos pressupostos apresentados no item xx, podemos concluir que [...]';

'Dado que partimos deste conjunto de premissas e de forma coerente chegamos a $<<\mathrm{P}>>$, podemos dizer que $<<$ P $>>$ foi obtido das mesmas';

'Iremos inicialmente caracterizar nosso entorno e em seguida iremos argumentar que, a partir do mesmo, poderemos afirmar com toda segurança que [...]';

'Feitas estas considerações, podemos concluir que [...]';

Estas e muitas outras formas de argumentação poderiam, se perdidas as características estilísticas (entre outras), serem reduzidas a: 
Metodologia Científica no Brasil

'Se partirmos das hipóteses [...], então podemos concluir que [...]', ou algo bastante semelhante. O que importa perceber é que, em qualquer sistema teórico, seja este na área de humanas, exatas ou biológicas, estamos a construir subjunções ou cadeias de subjunções (algumas das vezes, bijunções, mas estas sempre podem ser reduzidas a subjunções pelo axioma 8), isto é, estruturas semelhantes à acima descrita. Em geral, partimos de premissas, ou hipóteses, ou postulados, ou axiomas e, de forma concatenada e coerente (ou lógica, na má acepção do termo), conduzimos nosso discurso, seja ele qual for, até um outro ponto, ao qual denominamos de conclusão.

Neste sentido, já se pode observar que tanto Stiglitz e Walsh (2003) quanto Vieira (2004) entendem que teorias científicas (ou sistemas teóricos) são subjunções (implicações) ou cadeias de subjunções. Apontase aqui a ocorrência de um erro muito comum: não sabem alguns autores o que é uma hipótese, uma tese, e uma conclusão. Na subjunção

$$
\mathrm{h}_{1} \wedge \mathrm{h}_{2} \wedge \mathrm{h}_{3} \rightarrow \mathrm{c}
$$

os $h_{\mathrm{i}}(1 \leq \mathrm{i} \leq 3)$ são as hipóteses de trabalho e c é a conclusão deduzida do aceite dessas hipóteses. A subjunção como um todo é a tese ${ }^{5}$. É notório que as teses e/ou teorias científicas também podem estar na forma de bijunções (quando se usa o juntor “... se e somente se...” simbolizado por $\leftrightarrow$ ). Entretanto, devido ao fato de uma bijunção ser equivalente à conjunção de duas subjunções (dado que o enunciado $\mathrm{p} \leftrightarrow \mathrm{q}$ e o enunciado $(\mathrm{p} \rightarrow \mathrm{q}) \wedge(\mathrm{q} \rightarrow \mathrm{p})$ são equivalentes), entendemos que continuam a valer as afirmações dos autores citados com relação à natureza lógica das teorias e teses científicas, as quais são subjunções ou cadeias de subjunções. Ao apresentarmos à frente uma revisão do Método Hipotético-Dedutivo tal afirmativa ficará mais clara. Vejamos a continuação do texto de Vieira (2004, p. 41-42, grifo nosso):

Essa 'forma concatenada e coerente' aqui será denominada de 'procedimentos logicamente válidos'. Alguns procedimentos e operações derivam diretamente da teoria lógica, outras são construídas a partir desta em alguma área específica do conhecimento, mas todas têm uma característica lógica comum: elas não podem alterar o valor lógico dos enunciados ou ideias (por isso o uso da palavra 'coerência') ou, se alterarem, sempre no sentido do falso para o verdadeiro. Nunca há alteração de valor lógico do verdadeiro para o falso.

No mesmo sentido afirma Popper em Conjecturas e refutações (Popper, 1972, p. 348) ${ }^{6}$ :

A inferência lógica se faz de acordo com determinadas regras de inferência; será válida se a regra que utilizar for válida. E uma regra de inferência só será válida se nunca levar de premissas verdadeiras a uma falsa conclusão; em outras palavras, deverá sempre transmitir a verdade das premissas para a conclusão.

Vejamos Stiglitz e Walsh (2003, p. 17, grifo nosso): 
Se todos aqueles que têm formação universitária têm mais chances de conseguir emprego e Helena concluiu a faculdade, então ela tem mais chances de conseguir emprego do que alguém que não se formou. Os economistas recorrem às suas teorias para fazer previsões. Eles podem recorrer à teoria para prever o que aconteceria se um imposto fosse aumentado ou se as importações de automóveis estrangeiros fossem limitadas. As previsões de uma teoria têm a forma: 'Se aumentarmos um imposto num mercado concorrencial, então a produção diminuirá e os preços aumentarão'.

O que Stiglitz e Walsh (2003) estão chamando de previsões, Vieira (2004) e outros denominam teses de uma teoria e, concordando com os supracitados economistas, todos aqui já citados apontam a estrutura de subjunção (se...então...) como forma de uma teoria ou tese. Nesse sentido, é mister que sempre deixemos claro aos estudantes de Metodologia que uma tese é uma subjunção.

Explicitado o que se entende ser uma tese ou previsão científica, retornemos ao problema da demarcação. Acontece que não existe exatamente um consenso entre os professores brasileiros de Metodologia Científica acerca do que é e do que não é ciência. Não existe o que se denominaria de uma demarcação do conhecimento científico. Na verdade, parte significativa dos docentes dessa disciplina sequer sabe que o problema da demarcação é de grande complexidade. Prova inconteste disso é que as bibliografias utilizadas pela maioria dos docentes tratam a questão de forma simplista?

Karl Popper, por exemplo, colocou o problema da demarcação como um dos primeiros problemas a serem tratados em A lógica da pesquisa científica (Popper, 1993, p. 35):

Denomino problema de demarcação o problema de estabelecer um critério que nos habilite a distinguir entre as ciências empíricas, de uma parte, e a Matemática e a Lógica, bem como os sistemas 'meta-físicos', de outra. Esse problema foi abordado por Hume, que tentou resolvê-lo. Com Kant, tornou-se o problema central da teoria do conhecimento. Se, acompanhando Kant, chamarmos ao problema da indução 'problema de Hume', poderíamos chamar ao 'problema de Kant' o problema da demarcação.

E também em Conjecturas e refutações (Popper, 1972, p. 69):

Hoje sei, é claro, que esse critério de demarcação - o critério de 'testabilidade' ou 'refutabilidade' - está longe de ser óbvio; ainda hoje seu significado é raramente compreendido. Naquela época, em 1920, ele me pareceu quase trivial, embora resolvesse um problema intelectual que me havia preocupado profundamente, e tivesse consequências práticas óbvias (políticas, por exemplo). Mas não havia percebido ainda todas as suas implicações ou sua importância filosófica. Quando o expliquei a um colega, estudante de Departamento de Matemática (hoje um conhecido matemático na Inglaterra), ele sugeriu que o 
Metodologia Científica no Brasil

publicasse. Isso me pareceu absurdo, pois estava convencido de que o problema, tendo em vista sua importância para mim, já havia decerto preocupado numerosos cientistas e filósofos, que certamente já teriam chegado à minha solução, um tanto óbvia. O trabalho de Wittgenstein e o modo como foi recebido mostraram que não era bem assim; por isso publiquei minhas ideias treze anos depois, sob a forma de uma crítica ao critério de significação de Wittgenstein.

Não se pode atualmente, portanto, em uma aula ou texto didático de Metodologia Científica, fazer afirmações da ordem (Galliano, 1986, p. 32, grifo nosso): “Após o rápido exame do que é conhecimento geral e o científico em particular, voltemos nossa atenção para o método científico, suas propriedades e características gerais". Note-se que a demarcação sendo um problema complexo (tal como se vê em A lógica da pesquisa científica e em Conjecturas e refutações, ambos de Popper) foi, segundo as palavras do próprio autor do texto transcrito neste parágrafo, objeto de rápido exame. Note-se também que o referido autor categoricamente afirma (Galliano, 1986, p. 27, grifo nosso): "Enquanto não são comprovadas, as hipóteses deduzidas da investigação não podem ser consideradas científicas”. Assim, confunde a conclusão (ou o consequente) de uma subjunção com o conceito de hipótese; pois como vimos em Stiglitz e Walsh (2003), Vieira (2004) e Popper (1972), as hipóteses ficam no antecedente de uma subjunção (hipóteses são as premissas) e não na posição do consequente de uma subjunção (que é a conclusão e que será deduzida pela demonstração calcada no Método HipotéticoDedutivo).

Apesar de já termos feito o devido apontamento do que é uma hipótese em ciência, podemos ainda reforçar nossos argumentos. Vejamos o que afirma, no mesmo sentido, Luiz Pinguelli Rosa (2005, p.15): “Algumas premissas ou hipóteses serão formuladas a priori nesta introdução como pontos de partida, para buscar sustentar logicamente minhas teses e confrontá-las, ao longo do texto, com a história da Ciência e das teorias do conhecimento".

Continuando na questão do tratamento simplista ao problema da demarcação, vejamos outro texto no tópico O conhecimento científico (Cervo; Bervian, 1983, p. 9):

Hoje a concepção da ciência é outra. A ciência não é considerada como algo pronto, acabado ou definitivo. Não é a posse de verdades imutáveis. Atualmente, a ciência é entendida como a busca constante de explicações e soluções, de revisão e reavaliação de seus resultados e tem a consciência clara de sua falibilidade e seus limites. Nesta busca sempre mais rigorosa, pretende aproximar-se cada vez mais da verdade através de métodos que proporcionam um controle, uma sistematização, uma revisão e uma segurança maior do que possuem outras formas de saber não-científicas. Por ser algo dinâmico, a ciência busca renovar-se e reavaliar-se continuamente.

A ciência é um processo de construção. 
Os autores do referido texto didático encerram toda a nova concepção de ciência pós-Aristóteles nas poucas frases que transcrevemos. Nesse sentido, é que há a demarcação neste livro didático entre o que é e o que não é ciência. Mas vejamos mais detidamente as afirmações desse texto: (a) A ciência é um processo de construção; existem inúmeros processos de construção não científicos, apenas técnicos. Assim, não poderia haver tal afirmação em um parágrafo isolado no referido texto didático. O dinamismo não é característica somente da ciência, a linguagem também é dinâmica e apresenta permanente transformação. A noção de verdade, tal qual ainda era empregada por Kant, já sofreu pesado e definitivo revés com o surgimento das geometrias não-euclideanas. Foram, entretanto, felizes os autores em ressaltar o aspecto de busca de controle pela ciência. Quanto à consciência clara de seus limites (que a ciência teria), então os autores deveriam ter exibido tais limites, pois se esses são claros, então são facilmente passíveis de exibição. Em resumo, o texto não apresenta claramente a distinção entre o que é e o que não é ciência. Note-se que a presença de método e de sistemática não garante que um conhecimento seja científico. Quem desenha ou pinta seriamente possui método e sistemática, as tintas usadas na pintura atualmente são produtos da tecnociência, mas desenhar e pintar não são atividades científicas.

Já vimos que o desconhecimento do Método Hipotético-Dedutivo gera confusão terminológica entre o que são hipóteses (ou premissas), conclusões e teses. Temos a seguinte afirmação equivocada sobre o que seria uma hipótese em texto de Metodologia (Gil, 2009, p. 31):

Como ilustração, considere o seguinte problema: 'Quem se interessa por parapsicologia?' A hipótese pode ser a seguinte: 'Pessoas preocupadas com a vida além-túmulo tendem a manifestar o interesse por parapsicologia'. Suponha-se que mediante coleta e análise dos dados a hipótese tenha sido confirmada. Nesse caso, o problema foi solucionado porque a pergunta formulada pôde ser respondida.

Inicialmente, constatamos que o enunciado "Pessoas preocupadas com a vida além-túmulo tendem a manifestar o interesse por parapsicologia” não é uma hipótese e sim uma tese; que devido a uma característica de estilo está disfarçada como já se apontou em transcrição anterior. Vejamos esta mesma tese na forma padronizada de se...então...: "se existem pessoas preocupadas com a vida além-túmulo, então elas tendem a manifestar interesse em parapsicologia”. Dessa forma, a hipótese seria existem pessoas preocupadas com a vida além-túmulo. Mediante a referida coleta e análise de informações (tal levantamento de informações teria sido feito segundo os cânones de uma pesquisa e amostragem estatística), admitamos que se verificou estatisticamente que uma maioria significativa de pessoas que são preocupadas com o além-túmulo também são interessadas em parapsicologia. Dessa forma, a nossa tese standard está provada. Notório que faltaria ainda explicitar o conceito de pessoa com relação ao seu universo de pertença, 
tempo e lugar (como exemplos: atualmente pessoas preocupadas com a vida..., ou ainda: atualmente pessoas brasileiras preocupadas com a vida) e também o que se entende pelo termo/rótulo tendem. Acontece que tal tese ou teoria, corroborada por procedimento estatístico, não estaria respondendo minimamente ao problema inicialmente proposto que era: “Quem se interessa por parapsicologia?". Muitos outros grupos alheios à questão post mortem podem estar interessados em parapsicologia. Neste sentido, a modelagem do problema foi totalmente equivocada.

Em outro texto de Metodologia Científica, tem-se (Ruiz, 1996, p. 132): "Além de conhecer a natureza da ciência e do método científico é necessário meditar sobre o espírito científico”, nesse sentido colocado pelo autor, infere-se que já foi apresentada ao estudante a natureza da ciência e seu método e, agora, vai se passar ao estudo do espírito científico. A referência a espírito e as várias menções ao tomismo sugerem a possibilidade de se tratar de um teólogo culto, lato sensu, ensinando Metodologia Científica ${ }^{8}$. O texto em análise apresenta um discurso mais sofisticado do que os anteriores, mas isso não impede equívocos metodológicos. Vejamos, por exemplo, como o autor coloca a Matemática fora da Ciência de forma furtiva, embora tal posição possa ser inferida de seus argumentos com segurança. $\mathrm{O}$ artifício consiste em uma quase imperceptível troca de termos, de conhecimento científico, tomado lato sensu, para ciência empírica (Ruiz, 1996, p. 113, grifo nosso):

\begin{abstract}
O conhecimento científico atinge fatos concretos, positivos, fenômenos perceptíveis pelos sentidos, mediante instrumentos, técnicas e recursos de observação, enquanto o objeto da Filosofia são ideias, relações conceptuais, exigências de lógicas, não redutíveis a realidades materiais, por isso mesmo, não passíveis de observação sensorial, exigida pela ciência experimental.
\end{abstract}

Observa-se que as características atribuídas à Filosofia também poderiam ser atribuídas à Matemática. Portanto, com a assertiva anteriormente transcrita, infere-se facilmente que a Matemática não seria uma ciência. Ressalta-se que tal inferência é nossa, e não do autor, pois ele não admite a inferência/dedução como processo de validação científica, somente admite a experimentação. Vejamos:

\begin{abstract}
O método do conhecimento científico é experimental; a ciência caminha apoiada nos fatos reais e concretos e só afirma aquilo que a experimentação autoriza, enquanto a Filosofia usa o método racional no qual prevalece o processo dedutivo, que antecede a experiência, e não exige confirmação experimental, mas somente coerência lógica (Ruiz, 1996, p. 113-114, grifo nosso).
\end{abstract}

Há uma diferença significativa entre afirmar que "O método do conhecimento científico é experimental" e que o método do conhecimento científico inclui procedimentos experimentais nas ciências empíricas em paralelo (e em combinação) com a utilização de procedimentos dedutivos. Nas ciências formais não há experimentos ${ }^{9}$; e há várias outras ciências em que não há experimentos ou tais experimentos são muito diferenciados 
devido à natureza dos objetos tratados ou dos aspectos éticos envolvidos (Antropologia, Psicologia, História, Economia etc.). É claro que nessas áreas de conhecimento científico, sempre que possível, aguarda-se a confrontação da teoria (confrontação de suas hipóteses e as conclusões de suas hipóteses) pela experiência (e não somente pela experiência controlada, o experimento) ou pela observação e investigação do que já houve de experiência na história com vistas a serem fontes de novas deduções. Dessa forma, o mencionado autor acaba por não reconhecer o Método Hipotético-Dedutivo como científico.

Os textos didáticos analisados estão entre os mais frequentes nas bibliografias de Metodologia Científica no Brasil. Portanto, na situação atual, o viés simplista com que é tratado o problema da demarcação diminui e distorce o entendimento dos acadêmicos acerca da natureza da ciência e do seu método, desde o início.

Há vários autores de Metodologia Científica que deixam implícito que conhecem o Método Hipotético-Dedutivo e, nesse sentido, afirmam serem capazes de expor suas características gerais e propriedades ${ }^{10}$. Entretanto, não há sequer em seus textos uma demonstração do Método de Redução ao Absurdo ${ }^{11}$ (submétodo do que denominamos Método Hipotético-Dedutivo, ou mesmo do Método de Dedução Direta - MDD).

Umberto Eco (1976; 2010), também autor de livro de Metodologia, aponta em seu Tratado geral de Semiótica, com relação aos teóricos dos códigos, que havendo desconhecimento com relação ao cálculo proposicional, haveria dificuldade destes em minimamente reorganizarem suas regras de compreensibilidade, pois estariam presos a uma compreensão semântica típica do homem comum. Ora, é óbvio que não é a compreensibilidade de um homem comum que se quer desenvolver nos estudantes das universidades. Vejamos o alerta de Eco (1976, p. 53-54, grifo nosso) ${ }^{12}$ :

Suponhamos agora que alguém ponha a seguinte implicação: se Napoleão é um elefante, então Paris é a capital da França. Sabemos que, conforme as regras do cálculo proposicional, a implicação é Verdadeira mesmo não sendo Napoleão um elefante, e sê-lo-ia mesmo se Napoleão fosse um elefante, desde que Paris é de fato a capital da França. O entendido em cálculo proposicional não acharia nada risível nessa implicação: mas o teórico dos códigos teria boas razões para, quando menos, sorrir. E o mesmo aconteceria se (passando a proposições que não envolvem nomes próprios, que possuem propriedades especiais) se dissesse <se a neve é feita de chocolate, então os cães são mamíferos>.

O teórico dos códigos rir-se-ia em ambos os casos, pois acharia difícil imaginar algo que não concorde com a noção cultural de Napoleão ou da neve. O falante comum divide com seus iguais uma competência que atribui à neve várias propriedades, entre as quais falta a de ser composta de chocolate. [...]

Rimo-nos porque, embora compreendendo que a situação é inverossímil, percebemos o conteúdo do enunciado. Assustamo-nos porque, mesmo acatando a verossimilhança 
Metodologia Científica no Brasil

da situação, não logramos aceitar uma reorganização tão radical de nossa experiência semântica comum.

$\mathrm{O}$ enunciado, então, parece ridículo ou tragicamente significativo porque seu significado contrasta com as regras semânticas que compartilhamos. O significado não é inaceitável por ser incompreensível, mas por implicar, se aceito, a reorganização de nossas regras de compreensibilidade.

Assim, reafirmamos a necessidade de uma nova abordagem à disciplina de Metodologia Científica no sentido de contribuir para a reorganização das regras de compreensibilidade (tal como apontou Eco), abordagem que inclua uma apresentação mínima do Método Hipotético-Dedutivo. Observa-se, também, que vários cursos de Biblioteconomia, Arquivologia e Informática possuem, além da disciplina de Metodologia Científica, a disciplina de Lógica. Então, importa saber se está sendo ministrada a Lógica Fregeana ${ }^{13}$ ou algo anterior a Frege.

\section{Aspectos Lógicos do Método Hipotético-Dedutivo}

Apesar de existirem vários métodos de demonstração em Lógica, entendemos que o conjunto formado pelo Método de Dedução Direta e o Método de Redução ao Absurdo já é suficientemente representativo do que denominamos Método Hipotético-Dedutivo ${ }^{14}$.

Para desenvolvermos uma apresentação didática do Método de Dedução Direta, consideremos agora um universo de enunciados que denominaremos U. Todo construto teórico deve admitir um conjunto mínimo de princípios, postulados, axiomas, conceitos, definições e convenções. Estaremos aqui considerando em nossa teoria embrionária $\mathrm{T}$ (tal como na Figura 1) os princípios da Lógica Fregeana: Princípios do Terceiro Excluído, da Não-Contradição, da Identidade e as definições usuais dos juntores. Destes, para a perfeita compreensão do que será apontado adiante, somente serão necessários os conhecimentos dos princípios da Lógica (Princípio do $3^{\circ}$ Excluído: um enunciado pode ser valorado em Lógica Crisp como verdadeiro ou falso, não havendo outra situação possível. Princípio da Não Contradição: quando a um enunciado for atribuída certa valoração (caracterização), este enunciado não poderá assumir simultaneamente outra valoração. Princípio da Identidade: toda coisa é idêntica a si mesma. Isto é, um termo é idêntico a si mesmo, um enunciado é idêntico a si mesmo) e a definição do uso do juntor se... então... que colocamos na Figura 2.

Figura 1

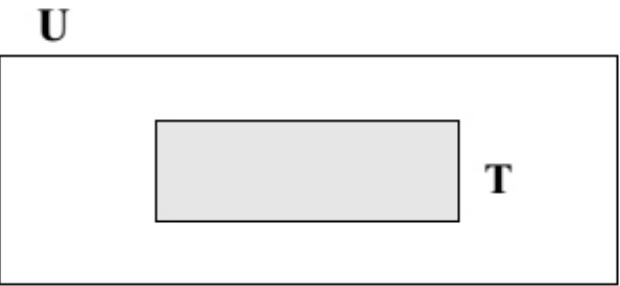

Fonte: Elaborado pelos autores.

248 Educação \& Realidade, Porto Alegre, v. 42, n. 1, p. 237-260, jan./mar. 2017. 
Figura 2

\begin{tabular}{|c|c|c|}
\hline $\mathbf{p}$ & $\mathbf{q}$ & $\mathbf{p} \rightarrow \mathbf{q}$ \\
\hline $\mathrm{V}$ & $\mathrm{V}$ & $\mathrm{V}$ \\
\hline $\mathrm{V}$ & $\mathrm{F}$ & $\mathrm{F}$ \\
\hline $\mathrm{F}$ & $\mathrm{V}$ & $\mathrm{V}$ \\
\hline $\mathrm{F}$ & $\mathrm{F}$ & $\mathrm{V}$ \\
\hline
\end{tabular}

Fonte: Elaborado pelos autores.

Dessa forma, o conjunto T da Figura 1 representa nossa teoria embrionária. Sendo assim, nosso construto teórico T é parte do universo U. Podemos enunciar agora que todo o universo, visto sob a ótica de T, é um universo de ideias verdadeiras ou falsas: as que estão em T são tomadas como verdadeiras (no sentido de serem compatíveis entre si) e as que estão em U, mas fora de T, podem ser verdadeiras ou falsas.

Nossa tarefa no desenvolvimento da Teoria T, assim como de qualquer outra teoria, é capturar outras ideias ou enunciados verdadeiros para o interior de T, ou melhor, para o escopo de nossa teoria. Como vimos anteriormente, os enunciados que requerem algum tipo de tratamento são as subjunções, isto é, enunciados moleculares que aqui serão tratados, esquematicamente, como $\mathrm{p} \rightarrow \mathrm{q}$. Se quisermos provar uma estrutura do tipo $\mathrm{p} \rightarrow \mathrm{q}$, geralmente supomos $\mathrm{p}$ fora de $\mathrm{T}$ (caso $\mathrm{p}$ pertença a $\mathrm{T}$, a explicação também vale e é de caráter mais simples). Este local de suposição é um campo teórico experimental que denominaremos $\mathrm{T}^{\mathrm{I}}$. Dessa forma, na perspectiva da Teoria T, dois valores são possíveis para p (verdadeiro e falso). Aos olhos deste campo teórico experimental $\mathrm{T}^{\mathrm{I}}$, o enunciado p é verdadeiro: é justamente o que distingue $\mathrm{T}^{\mathrm{I}}$ de $\mathrm{T}$, conforme mostra a Figura 3.

Figura 3

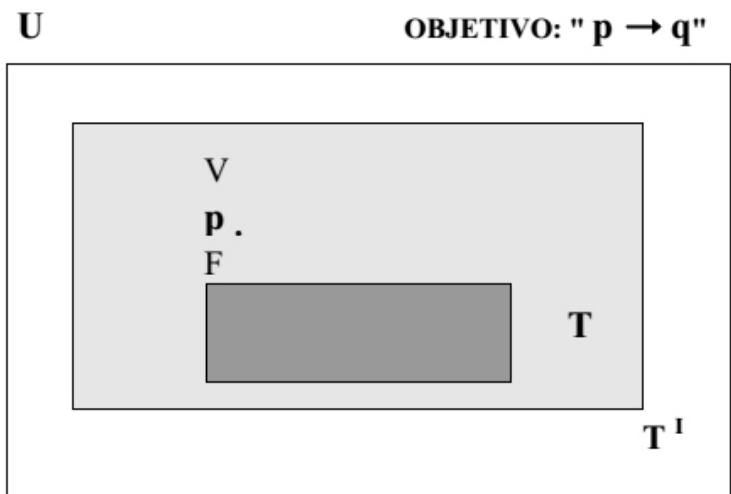

Fonte: Elaborado pelos autores. 
Metodologia Científica no Brasil

Aplicamos a p um conjunto de Operações Logicamente Válidas (OLVs). As OLVs formam uma categoria de transformações (ou operações ou procedimentos), realizadas sobre enunciados, transformações que nunca podem transformar um enunciado verdadeiro em um enunciado falso $^{15}$ (critério para classificar qualquer regra de transformação como OLV). Além das OLVs da própria Lógica ${ }^{16}$, todas as áreas de conhecimento científico possuem suas operações, transformações e procedimentos que podem ser, nesta forma de operar o Método Hipotético-Dedutivo, perfeitamente válidos, sejam as regras e transformação derivadas de procedimentos dedutivos ou indutivos. Portanto, uma grande vantagem sobre interpretações mais antiquadas do método. Neste sentido, valem perfeitamente as considerações de Popper; pois se uma tese ou teoria foi obtida através de procedimentos (ainda que seja somente um) derivados de indução, então a tese ou teoria não está provada, estando apenas corroborada enquanto valer a regra derivada do procedimento indutivo ${ }^{17}$. Para não sermos acusados de privilegiar as Ciências Exatas e Naturais, vamos utilizar um exemplo da área do Direito, em que as várias condutas dos indivíduos, realizadas no mundo concreto, funcionariam como premissas. Estas passariam por várias análises e transformações dos juristas; análises e transformações consideradas válidas na área jurídica (transformação seria o procedimento de interpretação padrão da doutrina jurídica sobre a conduta). Após certa conduta ser submetida a estes procedimentos, por exemplo, no âmbito penal e se tal conduta se verificasse como típica, antijurídica e culpável ${ }^{18}$, então se estabeleceria na ciência/doutrina jurídica a tese: "se houver a conduta X, então haverá o crime Y"19. As OLVs que permitiram a transformação do enunciado antecedente (premissa/hipótese: "houve a conduta X") para o enunciado consequente (conclusão: há o crime $Y$ ) são as práticas doutrinárias interpretativas de nosso ordenamento jurídico.

Ainda com relação ao exemplo na área jurídica, quando um indivíduo comete in concreto (nesse sentido, in concreto, deixou de ser mera hipótese utilizada no desenvolvimento de uma tese ou teoria) a referida conduta X, então se aplica o Modus Ponens (MP) e afirma-se que este indivíduo cometeu certo crime. A verificação de que um sujeito cometeu certa conduta no mundo real se faz por procedimentos empíricos (Inquérito Policial) e pelas teorias de imputação no Direito. O enunciado de que um sujeito particular cometeu uma certa conduta (comissiva houve a ação - ou omissiva - não se realizou a ação esperada), tida como crime, e que deve-se atribuir a ele uma certa sanção penal é, na verdade, um encadeamento de teses do tipo subjunção (se...então...).

Á guisa de esclarecimento, a operação Modus Ponens prevê o seguinte: se em dado momento verifica-se a validade de um enunciado $p$ $\rightarrow q$ e, ao mesmo tempo, a validade de $p$ (que é a premissa ou hipótese), segue-se que também se pode declarar a validade isoladamente de $q$ (Vieira, 2004, p. 38). A consequência isolada pelo Modus Ponens é ter ficado provado (no sentido jurídico e indutivo) o cometimento do crime. Em Direito há ainda outra subjunção a ser utilizada, segundo a qual dado o cometimento de um crime pelo tipo penal Y, por pessoa com conduta(s) 
com certa(s) característica(s) Z, então se fixará a pena (segundo o entendimento jurídico do magistrado sobre a conduta e o agente).

As OLVs são centrais na análise da moderna forma de operar o Método Hipotético-Dedutivo. Nesse sentido, já havia desde o primeiro quartel do Século XX desconfianças de que algo haveria de especial durante a passagem do antecedente para o consequente. Como já apontamos, mesmo Popper se equivocou na interpretação desse algo ao afirmar que a verdade era transmitida do antecedente para o consequente (Popper, 1972, p. 348, transcrição realizada anteriormente). Entretanto, há outro cientista que anteviu a situação que agora minuciosamente descrevemos. Vejamos Keynes em seu Tratado sobre probabilidades (Keynes, 1921, p. 3, tradução nossa):

Se nossas premissas consistem em um conjunto h qualquer de proposições, e nossa conclusão em um conjunto a qualquer de proposições, então, se o conhecimento de $h$ justifica uma crença racional em a de $\alpha$, nós dizemos que há uma relação de probabilidade de grau $\alpha$ entre a e h.

Aquilo que Keynes $(1921)^{20}$ entendeu como crença racional entre as premissas e a conclusão (o conhecimento de $h$ justifica uma crença racional em $a$ ), Popper (1972) entendeu como transmissão da qualidade verdade, e Vieira (2004) vê com clareza ser uma OLV. A grande vantagem do entendimento de Vieira, por nós adotado, é que questões metodológicas de várias áreas do conhecimento cientifico passam a comungar uma única terminologia e um conjunto único de mecanismos, o Método Hipotético-Dedutivo, com formato único e que atende às centenárias demandas (e reclamações) de que possuiriam natureza própria. Nesse sentido, a validação de teorias como científicas requer que sejam submetidas ao Método Científico, guarda-chuva de um grande número de procedimentos considerados válidos em ciência, cuja variante primaz é o Método Hipotético-Dedutivo. As validações das transformações nos diversos campos científicos, sejam regras, leis, propriedades ou procedimentos, continuarão a ocorrer internamente como já são realizadas, cabendo verificar se realmente nunca transformam verdadeiro em falso, a única exigência de segurança para que sejam consideradas OLVs. Considerem-se os seguintes exemplos:

Exemplo 1: Seja a operação $\mathrm{O}_{5}($ Compatibilidade com a Adição nos Reais, na Matemática)

\section{$\mathrm{V}$}

$2=2$ aplicando a transformação $\mathrm{O}_{5}$ temos $5=5$

$\mathrm{F}$

$2=3$ aplicando a transformação $\mathrm{O}_{5}$ temos $5=6$

Logo, a lei, regra ou propriedade $\mathrm{O}_{5}$ transforma o primeiro enunciado verdadeiro em verdadeiro e o segundo enunciado, falso em falso. Como não seria possível em um enunciado verdadeiro, como $2=2$, somar um mesmo 
valor a ambos os lados e isso possibilitar uma transformação de verdadeiro para falso, $\mathrm{O}_{5}$ é operação a ser aceita na categoria das OLVs.

Exemplo 2:

$\mathrm{V}$

$2=2$ aplicando ()$^{2}$ - potenciação de expoente 2 - temos $\quad 4=4$

$\mathrm{F}$

$2=3$ aplicando ()$^{2}$ - potenciação de expoente 2 - temos $\quad 4=9$

$\mathrm{F}$

$\mathrm{V}$

$2=-2$ aplicando ()$^{2}-$ potenciação de expoente 2 - temos $\quad 4=4$

Portanto, a lei, regra ou propriedade "potenciação de expoente 2 transforma o primeiro enunciado de verdadeiro para verdadeiro, o segundo enunciado de falso para falso e o terceiro enunciado de falso para verdadeiro. Mas não seria admissível em um enunciado verdadeiro, como $2=2$, aplicar um mesmo expoente a ambos os lados da igualdade e isso possibilitar uma transformação de verdadeiro para falso. Então a potenciação é operação a ser aceita na categoria das OLVs.

\section{Figura 4}

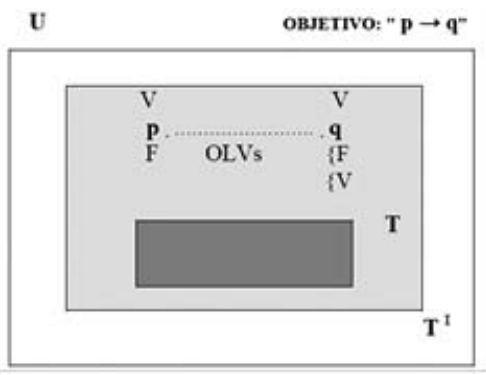

Fonte: Elaborado pelos autores.

Retornando a Figura 3, com o entendimento de que todas as transformações aplicáveis ao enunciado antecedente $p$ são do tipo OLV e que nosso objetivo com a aplicação de tais transformações seria a construção (ou captura) do enunciado $q$ para a Teoria $\mathrm{T}$, teríamos duas situações possíveis: obter, $q$ ou não obter $q$. O Método da Dedução Direta (MDD) é o caso em que obtemos $q$ a partir de $p$, considerando que atingimos sucesso em conseguir o enunciado $q$ mediante aplicações sucessivas de OLVs em $p$, como mostra a Figura 4. Isto é, se ao modificarmos $p$ por meio das operações (transformações, procedimentos, regras etc., que são validadas em cada área específica do conhecimento científico), e com isso gerarmos $q$, poderemos considerar que $p \rightarrow q$ é um enunciado verdadeiro. Por que motivo poderíamos tomar $p \rightarrow q$ como enunciado verdadeiro? Observemos a Figura 4 . Se eventualmente partirmos da verdade e só aplicarmos OLVs, então somente poderemos 
chegar à verdade. Por outro lado, se partirmos de um enunciado falso, então poderemos chegar a falso ou a verdadeiro. Mas se observarmos a Figura 2, veremos que as sequências da $1^{\mathrm{a}}, 3^{\mathrm{a}}$ e $4^{\mathrm{a}}$ linhas, que é o exposto na Figura 4, em que só aplicamos OLVs, sempre tornam a subjunção $p \rightarrow q$ um enunciado verdadeiro. Teremos então que $p \rightarrow q$ é verdadeiro, em face de se encontrar, obrigatoriamente, nas linhas 1, 3 ou 4 da Figura 2 . Sendo assim, o enunciado $p \rightarrow q$ mostra-se compatível com a axiomática e os demais enunciados e ingressa na Teoria $\mathrm{T}$.

Figura 5

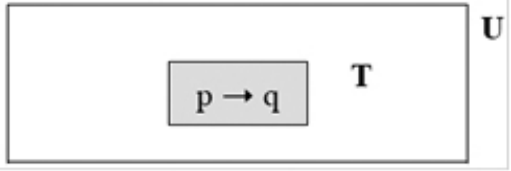

Fonte: Elaborado pelos autores.

Vejamos a seguir a situação em que a partir de $p$ não se consegue por meio somente da aplicação de OLVs chegar a $q$.

\section{O Método de Dedução Indireta}

Vimos, anteriormente, que no Método de Dedução Direta, após a suposição de $p$, o antecedente da subjunção objetivo, era possível chegar a $q$, consequente da subjunção objetivo, através de uma sequência de OLVs. Veremos agora o Método da Dedução Indireta, ou Método da Redução ao Absurdo, que é o caso em que não se consegue chegar diretamente ao consequente, por meio de aplicações de OLVs. Consideremos a figura 6.

Figura 6

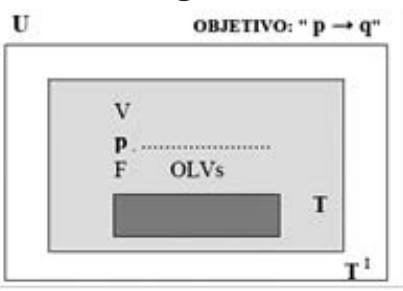

Fonte: Elaborado pelos autores.

A partir da Teoria T criou-se o campo experimental $\mathrm{T}^{\mathrm{I}}$ onde se admitiu o enunciado $p$. Sobre este se aplicaram diversas OLVs, mas não foi possível obter $q$, o consequente objetivo. O objetivo era demonstrar a subjunção $p \rightarrow q$, mas no desenrolar do método admitimos outros objetivos denominados objetivos provisórios. Dessa forma, é nítido que já optamos pelo Método da Dedução Direta, porém sua forma clássica, anteriormente apresentada, falhou. Pode-se, então, aplicar o Método da Dedução Indireta, que será uma espécie de algoritmo complementar do primeiro, para a obtenção do consequente objetivo q. No Método da Dedução Indireta temos que criar um segundo campo teórico experimental $\mathrm{T}^{\mathrm{II}}$, que é o $\mathrm{T}^{\mathrm{I}}$ adicionado de um elemento diferenciador. $\mathrm{O}$ elemento 
diferenciador, isto é, o elemento a ser admitido provisoriamente, será a negativa do consequente objetivo. Assim, se o consequente objetivo for $q$, admitiremos $\sim q$, como mostra a Figura 7 .

Figura 7

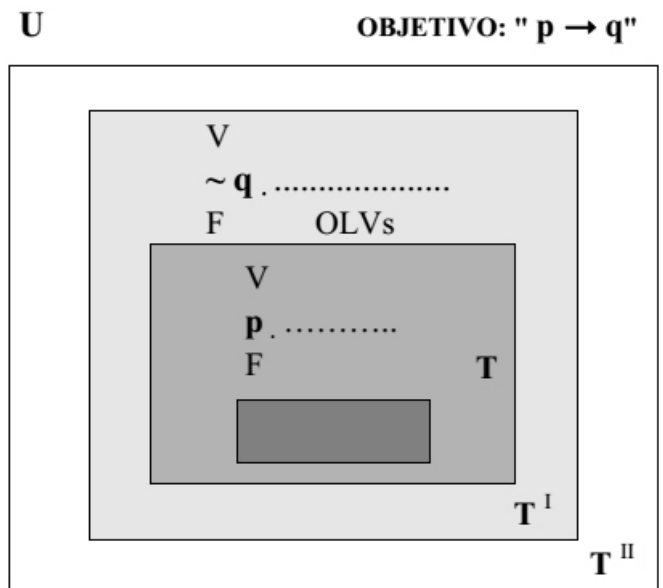

Fonte: Elaborado pelos autores.

Figura 8

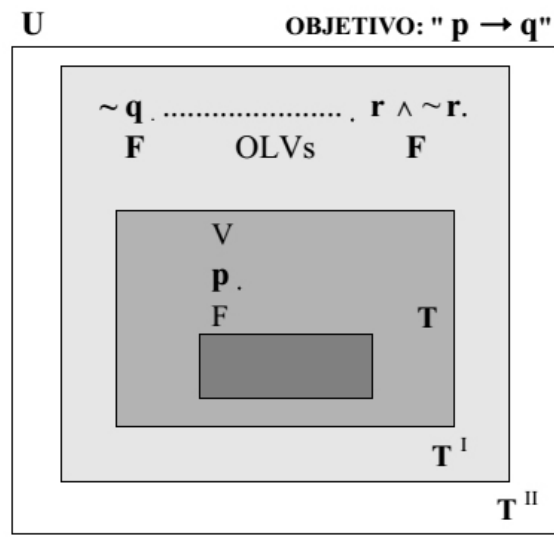

Fonte: Elaborado pelos autores.

Tendo havido a admissão da negativa do consequente objetivo, nossa busca passa a ser por uma estrutura de enunciados que tenham a forma $r \wedge \sim r$. Assim, o procedimento consistirá em aplicar OLVs até obter tal estrutura. Uma vez que $r \wedge \sim r$ é sempre falsa e somente foram aplicadas OLVs, depreende-se que necessariamente partimos de uma estrutura falsa, isto é, $\sim q$ é falso, como é ilustrado na Figura 8.

Como $\sim q$ é falso, seu enunciado contrário, $q$, é verdadeiro. Nesse momento, encerra-se propriamente o Método de Dedução Indire$\mathrm{ta}^{21}$. Esta obtenção da veracidade do enunciado $q$ é válida em todos os 
campos teóricos, sem exceção. Por uma questão de sistematização de procedimentos, e por não ser esse nosso objetivo principal, admitimos a veracidade de $q$ em campo teórico imediatamente inferior. No nosso modelo, o campo teórico imediatamente inferior a $\mathrm{T}^{\mathrm{II}} \mathrm{é}^{\mathrm{T}}{ }^{\mathrm{I}}$, como na Figura 9 .

\section{Figura 9}

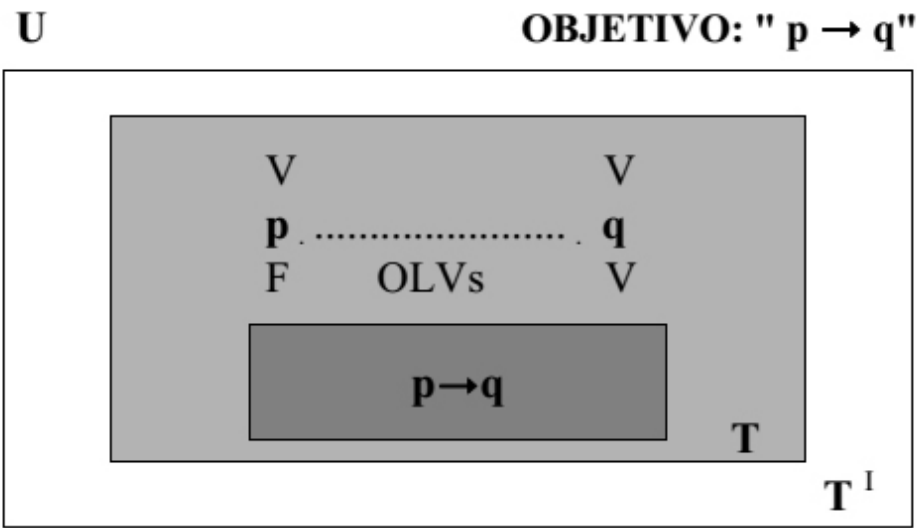

Fonte: Elaborado pelos autores.

Observemos que $q$ é sempre verdadeiro. Daí, retornando ao MDD, e pela definição do se...então... (Figura 3), temos que a subjunção $p \rightarrow q$, nosso objetivo principal, é verdadeiro.

\section{Conclusão}

Procuramos no presente artigo contribuir para a eliminação ou minimização de equívocos frequentes dos textos adotados nas disciplinas de Metodologia Científica no Brasil. Tais erros no processo de ensino-aprendizagem brasileiro são, ao nosso entendimento, de grande repercussão socioeconômica, mesmo que não sejam causados deliberadamente pelas pessoas que os praticam, como docentes, pesquisadores e autores. Provavelmente são derivados do excesso de informação, inclusive de informações e terminologias ultrapassadas, ultrapassadas a ponto de serem anteriores ao surgimento da Lógica Fregeana. Apesar disso, observa-se no Brasil um quadro geral de ausência de debates e de inação em quase todos os setores com relação à referida disciplina.

Por meio da exposição sintética do Método Hipotético-Dedutivo tornou-se claro que antigas querelas acerca da diversidade dos métodos das várias ciências não dizem respeito à fase lógica do método e sim à verificação da validade dos enunciados (hipóteses e conclusões) e à construção das Operações Logicamente Válidas. Observou-se, por exemplo, que apesar de a maioria dos cursos na área da Ciência da Informação possuir disciplinas de Lógica, pretensamente complementando as de Metodologia, tais disciplinas são ainda frequentemente ministradas 
Metodologia Científica no Brasil

com base na Lógica Aristotélica, não se prestando sequer para preparar um estudante para concursos públicos com um conjunto de conhecimentos denominado geralmente de raciocínio lógico e, portanto, muito menos para preparar um futuro docente em Metodologia.

São várias as áreas do conhecimento que podem dar contribuições importantes à Metodologia Científica, mas os apontamentos do presente trabalho deveriam ser mais bem observados. Em cursos ligados à computação há forte recomendação desse estudo de Lógica pela Sociedade Brasileira de Computação e, como vimos anteriormente, em Engenharia de Produção há reiterados esforços em Metodologia; portanto, entendemos que seus pesquisadores, por exemplo, podem se integrar mais amplamente aos esforços de outros cursos com vistas ao aprimoramento da formação de estudantes de graduação e pós-graduação. Os cursos de Ciências Jurídicas, ao nosso entendimento, devem rever o tratamento dispensado a disciplina de Metodologia que, muitas vezes, é ministrado com o despreparo e falta de cuidado tal como apontamos no presente trabalho.

Como corolário dessas teses, propomos que o aprimoramento da referida disciplina seja uma política pública em Educação.

Finalmente, mostramos que o simplismo com que é tratado o problema da demarcação da Ciência é, ao mesmo tempo, cômodo e ilusório, porque a simplicidade pretendida em vez proporcionar clareza e segurança aos iniciantes em pesquisa científica e de despertá-los para a possibilidade de desenvolverem esse tipo de trabalho nos diversos campos da Ciência, constitui, na verdade, a perda de uma oportunidade valiosa. Há diversas questões epistemológicas e metodológicas a serem enfrentadas nos variados campos do saber e, por isso, a disciplina de Metodologia Científica constitui oportunidade valiosa para o fomento da investigação. Esta disciplina pode fornecer o conhecimento necessário para o trabalho individual ou em grupo e pode proporcionar uma postura crítica em relação às práticas acadêmicas próprias e de terceiros.

Aqui não buscamos investigar ou resolver o Problema da Demarcação, apenas apontamos as sucessivas omissões dos textos ou que é usual uma forma simplista de abordar o referido problema. Entretanto tratamos, de forma objetiva e didática, do Método Hipotético-Dedutivo (sua parte lógica) e de suas modalidades MDD e MRA devido à sua destacada importância para o trabalho científico, mostrando como esses saberes podem ser desmistificados e colocados ao alcance de alunos e pesquisadores em formação em universidades e centros de pesquisa. Nesse sentido, tratamos aqui, de forma moderna, atual, e intelectualmente ergonômica da hipótese de que há um elo comum entre todas as ciências, hipótese que, ao nosso entendimento, é o principal argumento para a existência da disciplina de Metodologia Científica para quase todos os cursos de graduação e pós-graduação e que é um passo importante se quisermos alcançar essa nova fase do desenvolvimento científico, pósinterdisciplinar, que Krakauer (2011) denominou de transciência. Assim, o tratamento sugerido para a disciplina favorece o amadurecimento de práticas interdisciplinares, pois, com a normalização (no sentido de pa- 
dronização) de procedimentos científicos, haverá maior compreensão mútua entre profissionais de diferentes áreas; o que, por consequência, permitirá a facilitação de práticas isomórficas, de embates epistemológicos, de construções de estruturas científicas verdadeiramente sistêmicas, com reestruturações teóricas de vários campos de saber com base no aproveitamento de esforços já realizados em outros campos do conhecimento.

Recebido em 26 de março de 2015 Aprovado em 29 de setembro de 2015

\section{Notas}

1 Texto original de Krakauer (2011, p. 2): "I believe we are entering a period of transcience, where it is becoming necessary that training in areas with fundamental mathematical, computational, and logical principles should be emancipated from a single class of historically contingent case studies. For example, statistical physics will continue to be every bit as useful in understanding social phenomena as it traditionally has been in studying properties of condensed matter".

2 "Simplismo" está sendo considerado aqui como um vício de raciocínio derivado da falta de utilização, por desprezo ou despreparo, de um ou mais elementos necessários à solução de um dado problema.

3 Coordenação dos Programas de Pós-Graduação em Engenharia da Universidade Federal do Rio de Janeiro.

4 Stiglitz recebeu em 2001 o Prêmio Nobel de Economia.

5 No mesmo sentido de Stiglitz \& Walsh (2003) e Vieira (2004) temos Joseph Dopp (1970, p. 5).

6 Existem diferenças entre a compreensão de Vieira e de Popper com relação ao que faz uma regra de inferência, apesar de que ambos afirmam que: uma regra de inferência ou de dedução válida nunca transforma um enunciado verdadeiro em um falso. No mesmo sentido concorda Newton da Costa em seu Ensaio sobre os fundamentos da Lógica (Da Costa, 1994, p. 67). Popper aponta a existência de uma transmissão de veracidade das premissas para a conclusão. Para Vieira isso não ocorre, a qualificação de veracidade de um enunciado não é algo que se transmita. $\mathrm{O}$ que ocorre é saber se a regra de inferência utilizada possui ou não o poder de transformar (e não de transmitir) um enunciado verdadeiro em um outro enunciado com qualificação falso. Em Vieira (2004, p. 41-44), se estiver provado (ou corroborado, no sentido de Popper se a regra de transformação tiver sido obtida empiricamente) que a transformação gerada pela regra de inferência sobre um enunciado nunca é no sentido de transformar verdadeiro em falso, podendo haver: transformação de verdade em outra verdade ou mesmo de uma falsidade em uma verdade; então a essa regra de transformação será dita uma operação logicamente válida (OLV) e poderá ser amplamente utilizada no processo dedutivo. Popper por não conhecer à época o moderno conceito de OLV não vislumbrou que os operadores logicamente válidos (ou regras de inferência) poderiam inclusive transformar um enunciado falso em um outro enunciado de qualificação verdadeiro. Vejamos um exemplo que refuta Popper e, neste sentido estrito, dando razão a Vieira: Se tomarmos como premissa o enunciado $2=-2$ (enunciado fechado que sabemos ser falso) e sobre ele aplicarmos a potenciação de grau dois em ambos os lados da igualdade, o que é reconhecido como operações válidas da Matemática têm-se: $(2)^{2}=(-2)^{2}$, então teremos ao final $4=$ 4 (enunciado fechado que sabemos ser verdadeiro) e a tese " $2=-2 \rightarrow 4=4$ " fica 
Metodologia Científica no Brasil

plenamente demonstrada. Note-se que a tese é verdadeira ainda que na prática (pela via da Matemática usual onde $2 \neq-2$ ) não possamos aplicar Modus Ponens.

7 Entre inúmeros outros exemplos possíveis temos: material didático da UNOESC (Brasil) de Metodologia Científica (disponível em:<http://people.ufpr.br/ felipe/ Apost_Metod_Cient-1.pdf $>$. Acesso em: 26 jul. 2013). Há ainda casos em que um livro equivocado de Metodologia é citado em outro livro, justamente no ponto do equívoco, tal como o popular Ruiz, citado por Lakatos e Marconi (2003, p. 78), que apontam justamente o ponto equivocado do primeiro autor.

8 O curriculum do autor, no site da Editora Atlas, é mais uma forte indicação disto (Disponível em: <http://www.editoraatlas.com.br/Atlas/webapp/curriculo_autor. aspx?aut_cod_id=457>.Acesso em: 17 jul.2013).

9 Portanto, conforme já havíamos apontado, para o referido autor Matemática não é Ciência.

10 Como exemplo: Galliano (1986, p. 32).

11 Indicado com a sigla MRA ou como MDI (Método de Dedução Indireta).

12 O termo risível na citação de Eco está sendo usado por este no sentido de grotesco ou ridículo; pois este entende que quem compreende ser risível, ou grotesco, ou ridículo o referido enunciado, riria de sua enunciação. O que aponta não ser o caso de quem compreende Lógica (este não riria) e já os teóricos dos códigos, por desconhecerem as regras do cálculo proposicional achariam, ingenuamente, graça no enunciado.

13 A Lógica Fregeana também é denominada de Moderna ou Lógica Crisp, optouse pela última.

14 Com relação aos testes das hipóteses, que também entendemos fazerem parte do Método Hipotético-Dedutivo no caso das ciências empíricas, diremos brevemente: (1) os testes empíricos das hipóteses, pela experimentação ou pela experienciação, apenas corroboram (no sentido que Popper utiliza o termo) tais hipóteses e, com isso poder-se-á realizar o Modus Ponens e validar o enunciadoconclusão isoladamente; (2) caso as hipóteses da tese em análise sejam invalidadas por testes empíricos, então o enunciado tese, ainda que logicamente válido, não é um enunciado científico (houve, nesse sentido a falseabilidade em função da testabilidade, mas poder-se-ia aqui tecer várias outras considerações); (3) mesmo que as hipóteses tenham sido isoladamente validadas deve-se, após a aplicação do Modus Ponens (com a consequente validação lógica do enunciado tomado isoladamente), verificar a testabilidade da conclusão (se empiricamente é válida e também se na teoria em que o enunciado-conclusão estaria sendo admitido não surgiram quaisquer contradições com outros resultados precedentes). Acontece que tais testabilidades devem ser feitas pelos profissionais do entorno do conhecimento (químicos, físicos, sociólogos, juristas, economistas, engenheiros cientistas da informação etc., e não por um metodólogo sem a formação específica).

15 Podem transformar um enunciado verdadeiro em outro verdadeiro, um enunciado falso em outro enunciado falso e até mesmo transformar um enunciado falso em um enunciado verdadeiro.

16 Como, por exemplo: Modus Ponens, E-Introdução, E-Eliminação, OuIntrodução, Ou-Eliminação, Contrapositiva, etc.. Esta terminologia é bem ergonômica e é encontrada completa no método semiótico estruturado (Vieira, 2004), mas pode ser vista também em outros autores.

17 Enquanto houver confirmações/corroborações pelos experimentos (Popper, 1993). Nós acrescentaríamos confirmações/corroborações pela experiência, 
dado que algumas áreas do conhecimento científico não são sujeitas a confirmação por experimentos e somente a experiência da vida humana ao longo da história poderá confirmar ou refutar o dito ou a OLV empregada.

18 Conceitos jurídicos não são conhecidos como deveriam. Assim, à guisa de rápido aclaramento, matar alguém não é necessariamente crime, é apenas um tipo penal descrito no artigo 121 do Código Penal pátrio (Brasil, 1940). Se alguém (o imputado de certa conduta) cometer um fato típico (matar alguém), porém, houver no evento uma exclusão de antijuridicidade (tipo a legítima defesa), então o imputado não cometeu um crime no sentido jurídico. Assim, pode-se dizer que crime é toda conduta típica, antijurídica e culpável.

19 No tipo penal estelionato (art. 171 do Código Penal), por exemplo, os juristas estabelecem, entre dezenas de variações de condutas próximas ao tipo penal (idealisticamente pensado), quais as condutas que participariam da subjunção e quais, no entendimento doutrinário, estariam fora da subjunção (se houver condutaX, então há o crime Y). O estudo destas subjunções são os ensinamentos doutrinários e constituem o cerne do ensino jurídico. Tal estudo doutrinário não está originalmente na forma de subjunções (implicações), entretanto, é facilmente compreendido como uma subjunção (vide obra de Hans Kelsen).

20 Texto original (Keynes, 1921, p. 3, grifo nosso): "Let our premisses consist of any set of propositions $\underline{h}$, and our conclusion consist of any set of propositions

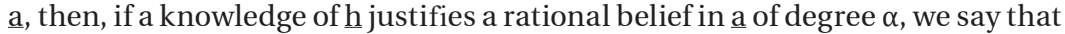
there is a probability-relation of degree $\alpha$ between $\underline{a}$ and $\underline{h}$ ".

21 Caso não se consiga obter o enunciado "r $\wedge \sim \mathrm{r}$ ", então duas situações são possíveis. A primeira, mais frequente, é que o enunciado " $\mathrm{p} \rightarrow \mathrm{q}$ " é falso. A segunda, que ocorreu com Isaac Newton, surge do desconhecimento de OLVs (não ainda inventadas); Newton, para as teses da Teoria da Gravitação, resolveu o problema criando as OLVs do Cálculo Diferencial e Integral.

\section{Referências}

BERTALANFFY, Ludwig Von. Teoria Geral dos Sistemas. Rio de Janeiro: Vozes, 2012. BOBBIO, Norberto. Teoria do Ordenamento Jurídico. São Paulo: Edipro, 2011.

BRASIL. Decreto-Lei n. 2.848, de 7 de dezembro de 1940. Código Penal. Diário Oficial [da República Federativa do Brasil], Rio de Janeiro, 31 dez. 1940. Seção 1. P. 23911.

CERVO, Amado Luiz; BERVIAN, Pedro Alcino. Metodologia Científica. Rio de Janeiro: McGraw-Hill, 1983.

COPPE/UFRJ. Programa de Engenharia de Produção. Catálogo COPPE 2001. Rio de Janeiro: Coordenação dos Programas de Pós-Graduação em Engenharia: COPPE//UFRJ, 2001. Disponível em: <http://www.coppe.ufrj.br/coppe/catalogo/producao.pdf $>$. Acesso em: 29 ago. 2014.

DA COSTA, Newton Carneiro Afonso. Ensaio Sobre os Fundamentos da Lógica. São Paulo: HUCITEC, 1994.

DOPP, Joseph. Noções de Lógica Formal. São Paulo: Editora Herder, 1970.

ECO, Umberto. Como se Faz uma Tese. São Paulo: Editora Perspectiva, 2010.

ECO, Umberto. Tratado Geral de Semiótica. São Paulo: Editora Perspectiva, 1976.

FREGE, Friedrich Ludwig Gottlob. Lógica e Filosofia da Linguagem. São Paulo: Cultrix/EDUSP, 1978.

GALLIANO, Guilherme Alfredo. O Método Científico: teoria e prática. São Paulo: Ed. Harbra, 1986.

Educação \& Realidade, Porto Alegre, v. 42, n. 1, p. 237-260, jan./mar. 2017. 
GIL, Antonio Carlos. Como Elaborar Projetos de Pesquisa. São Paulo: Atlas, 2009. KEYNES, John Maynard. A Treatise on Probability. Londres: MacMillan, 1921. Disponível em: <http://www.gutenberg.org/files/32625/32625-pdf.pdf>. Acesso em: 01 jul. 2014.

KRAKAUER, David C. Transcience: disciplines and the advance of plenary knowledge. SFI Bulletin, Santa Fé (EUA), Santa Fé Institute, 2011. Disponível em: <http://www.santafe.edu/media/bulletin_pdf/sfi_bulletin_spring_2011. pdf $>$. Acesso em: 06 jun. 2014.

LAKATOS, Eva Maria; MARCONI, Marina de Andrade. Fundamentos de Metodologia Científica. São Paulo: Atlas, 2003.

PINGUELLI ROSA, Luiz. Tecnociências e Humanidades: novos paradigmas, velhas questões. São Paulo: Paz e Terra, 2005.

POPPER, Karl Raimund. ALógica da Pesquisa Científica. São Paulo: Ed. Cultrix, 1993. POPPER, Karl Raimund. Conjecturas e Refutações. Brasília: Ed. UnB, 1972.

RUIZ, João Álvaro. Metodologia Científica: guia para eficiência nos estudos. São Paulo: Editora Atlas, 1996.

STIGLITZ, Joseph Eugene; WALSH, Carl Eugene. Introdução à Macroeconomia. Rio de Janeiro: Campus, 2003.

VIEIRA, Américo Augusto Nogueira. Lógica: método semiótico estruturado. Rio de Janeiro: Sarau Cultural, 2004.

Américo Augusto Nogueira Vieira é Pós-Doutor em Ciência da Informação (PPGCI/UFPB), Pós-Doutorando em Direito (PPGCJ/UFPB), Doutor em História das Ciências, das Técnicas e Epistemologia (COPPE/UFRJ). Mestre em Engenharia de Produção (COPPE/UFRJ), Mestre em Memória Social e Documentação (UNIRIO). Professor de Direito da UFPR.

E-mail: americo_vieira@yahoo.com.br

Ademir Clemente é Pós-Doutor em Economia (University of London, UK), Pós-Doutor em Engenharia de Produção (COPPE/UFRJ), Doutor em Engenharia de Transportes (COPPE/UFRJ), Mestre em Engenharia de Produção (COPPE/UFRJ). Professor de Economia e Contabilidade da UFPR.

E-mail: ademir@ufpr.br

Guilherme Ataíde Dias é pesquisador pelo CNPq, Pós-Doutor em Ciência da Informação (UNESP/Marília), Doutor em Ciência da Informação (USP). Mestre em Organization \& Management (Central Connecticut State University, USA). Professor de Ciência da Informação na UFPB.

E-mail: guilhermeataide@gmail.com

Marcílio Toscano Franca Filho é Pós-Doutor em Direito (Instituto Universitário Europeu, Itália), Doutor em Direito (Universidade de Coimbra, Portugal), Mestre em Direito (PPGCJ/UFPB). Procurador do Ministério Público junto ao TCE/PB. Professor de Direito da UFPB.

E-mail:mfilho@tce.pb.gov.br 